\title{
Implementation of two-phase flow models for recycled materials in embankments
}

\author{
João A.R. Machado ${ }^{1}$, Ambria Vasquez ${ }^{2}$,Wing Shun $\mathrm{Kwan}^{3 *}$, Jose M. Fuentes ${ }^{4}$, and Gustavo Menezes ${ }^{5}$ \\ ${ }^{1}$ RDP Geotechnical Engineer, Geocomp Corporation, Acton, MA, USA, and Former Research Assistant, Center for Energy and \\ Sustainability, California State University, Los Angeles, USA \\ ${ }^{2}$ Graduate Research Assistant, Dept. of Civil Engineering, California State University, Los Angeles, USA \\ ${ }^{3 *}$ Assistant Professor, Dept. of Civil Engineering, California State University, Los Angeles, USA \\ ${ }^{4}$ Undergraduate Research Assistant, Dept. of Civil Engineering, California State University, Los Angeles, USA \\ ${ }^{5}$ Professor, Dept. of Civil Engineering, California State University, Los Angeles, USA
}

\begin{abstract}
Recycled materials like Bauxite Residue (Red Mud) and Fly Ash are prevalent in recent feasibility studies on reused materials in geotechnical engineering applications. Red Mud is a mining waste from aluminum manufacturing, and Fly Ash is a by-product of coal combustion in power plants. Nevertheless, to fully reveal the feasibility of using those materials for constructing above-ground earth structures, a better understanding of their unsaturated performance in geo-structure is essential. While some popular empirical models (e.g., van Genuchten 1980) in Soil Water Retention Curves (SWRC) are commonly used to describe soils' unsaturated conditions, those models may not apply to unique materials like Red Mud and Fly Ash. Recently, SWRC curves of both materials were acquired through the Steady-State Centrifuge (SSC) Unsaturated Flow Apparatus (UFA) procedure at Cal State LA. The experimental data were used to develop analytical models following the van Genuchten model. Using a finite-difference software (FLAC) and obtained SWRC curves, this study performed numerical simulations of embankments filled with Fly Ash and Red Mud, comparing it with an embankment filled with typical silty soil with the same dimensions and conditions. Results showed seepage flow rates for Fly Ash and Red Mud are higher when used as fill material as above-ground embankments.
\end{abstract}

\section{Introduction}

In the urge for sustainability and more efficient processes, reusing materials that are considered residues or waste could lead to reducing the need for unsustainable exploration of earth resources, while reducing costs and improving efficiency. Bauxite residue, commonly known as Red Mud (RM), is a slurry by-product mining waste generated during alumina production, in a Bayer Process [1], with 120 million tons being generated yearly. Previous studies have shown great potential to reuse RM in various industries like construction, transportation, and filling materials for levees and dikes, creating a win-win situation for mining companies and these industry sectors. [2]. Another typical type of residue, fly ash, is a byproduct from coal combustion in power generation plants, with more than 100 million tons being produced every year [3]. Fly ash can potentially be reused as a concrete admixture or a soil enhancement product.

Considering that large volumes of these waste products could be used as filling materials for levees, dikes, or embankments, they could be changed from production costs or environmental issues into valuable resources for Civil Engineering usage [4]. However, there are limitations that may hinge on the usability of these recycled materials. Since the types of geotechnical structures mentioned earlier are constructed above ground, they will experience changes in the saturation levels, and therefore understanding their behavior under unsaturated conditions is paramount. A common method of modeling soil behavior under these conditions is the Soil Water Retention Curve (SWRC). This unsaturated soil mechanics approach determines how the soil responds to different suction or matric potential levels under constant change in the saturation levels [5]. This is especially true when the existing analytical models that describe the unsaturated soil behavior may not be well calibrated for uncommon materials like Red Mud, a highly alkaline type of product, or Fly Ash, a clay-like material generated during coal production, because of the limited amount of high-quality experimental data. Therefore, there is a need to investigate the residues' unsaturated hydraulic performance as a geo-structure like embankments.

When utilizing materials with unknown unsaturated characteristics, the primary question is the two-phase flow behavior, involving wetting and non-wetting fluid transport, relative permeability, and capillary pressure laws. FLAC, a geotechnical engineering computation software developed by Itasca [6] with a two-phase option

\footnotetext{
$\overline{{ }^{*} \text { Corresponding author: wkwan4@,calstatela.edu }}$
} 
using the van Genuchten model to simulate two-phase flow calculations, is adopted for this study.

van Genuchten's [7] model employed in FLAC is the most common soil-water retention model, which works for various soil types after calibrating its shape factors. The model calculates nonlinear parameters for water retention curves to standardize its use on unsaturated soil characterizations [8]. Experimental data can be used to calibrate these parameters.

This study came up with van Genuchten parameters for Red Mud and Fly Ash based on the steady-state centrifuge data from Machado et al. [2] and Sindi [9] and performed numerical simulations in FLAC. Seki Webtool [10], a web-based data fitting tool, was used to obtain analytical parameters for unsaturated soil modeling, including the popular van Genuchten model, through the inputs of measured experimental data.

A simple and idealized embankment structure was used to evaluate the unsaturated hydraulic performance of Red Mud and Fly Ash being used as fill materials. We also considered other common soils, such as Sand, Silt, and Clay. Despite the centrifuge data showing the two residues have similar unsaturated hydraulic characteristics to fine-grained soils, the numerical simulations in this study show that Red Mud and Fly Ash are more permeable when used as fill materials in the above-ground embankments. Therefore, Red Med and Fly Ash may not able to retard as much flow as Silt in embankments.

\section{Materials and methods}

The Bauxite residue for this study was obtained from Golder Associates Inc. It was collected from a bauxite ore refining facility on the Eastern side of India. Bulk samples were collected, and due to confidentiality with the refinery's restriction, additional information is not available.

Fly Ash samples were acquired as a partnership with the University of South Carolina for Steady-State Centrifugations tests, realized by Sindi [9]. They were obtained in various power plants across the U.S., and due to confidentiality, they cannot be presented. The procedures and methods were the same as those used for Red Mud, making them possible to be compared.

A set of laboratory tests was realized utilizing a SteadyState Centrifugation (SSC) unsaturated flow apparatus (UFA) to understand the unsaturated characteristics of Red Mud and Fly Ash. As Red Mud is a highly alkaline material, tests were also performed with $\mathrm{pH}$-reduced samples, neutralized by mixing with saline and gypsum solutions [2].

\subsection{Steady-state centrifugation}

Cal State LA's SSC-UFA facilities can achieve a rotational speed of up to $4000 \mathrm{rpm}$ and hydraulic conductivity values as low as $3.7 \times 10^{-9} \mathrm{~cm} / \mathrm{s}$ were utilized to perform all tests following ASTM D6527 [11] to determine the unsaturated hydraulic conductivity $(\mathrm{K})$ and the matric potential $(\Psi)$ as functions of volumetric water content $(\theta)$. The hydraulic conductivity is controlled by adjusting the water flow rate and the SSC-FA rotational speed until the volumetric water content achieves a steady-state condition, determined by monitoring the sample's weight. Matric Potential levels can be applied to the samples by increasing the centrifuge rotation. The SSC-UFA tests result in the hydraulic conductivity plot and soil water retention curve (SWRC). This process was performed for both materials, Red Mud and Fly Ash. For Red Mud, a set of tests was also realized with reduced $\mathrm{pH}$ samples since bauxite residue is a very high $\mathrm{pH}$ mining waste. Machado et al. [2] documented two laboratory techniques for $\mathrm{pH}$ reduction: mixing Red Mud with saline or gypsum solutions. Experimental results show that the unsaturated hydraulic characteristics of Red Mud are slightly changed after $\mathrm{pH}$ treatments. We only considered untreated Red Mud in this study.

\subsection{Fast lagrangian analysis of continua (FLAC)}

The Fast Lagrangian Analysis of Continua (FLAC) software package uses the finite-difference method to solve the geotechnical engineering problem and simulates seepage through an embankment for this research project. The program allows for solving unsaturated problems by incorporating the van Genuchten model to describe the relative permeability and capillary pressure laws [6]. FLAC is a menu-driven program with FISH functions being available for use with designing models. In our FLAC analyses, the two-phase flow was used to determine the seepage through an embankment based on the different soil types and van Genuchten parameters for each.

\subsubsection{Embankment Simulations}

The numerical simulations were carried out for five material types: 1) Sand, 2) Silt, 3) Clay, 4) Red Mud (RM), and 5) Fly Ash (FA) as the embankment's fill material. For the simulations, rectangular embankments sit on top of an impermeable soil layer. The setup of the embankment was adapted from an example in the FLAC manual [12], which followed an example of modeling an embankment with a material of Bandelier Tuff [13]. The Tuff embankment has a baseline dimension of $6 \mathrm{~m}$ height and $9 \mathrm{~m}$ width and can stand on its own with vertical walls (Fig. 1a). Initially, the embankment was dry, and the water table was located at $1.2 \mathrm{~m}$ above the impermeable base (Fig. 1a). Then, the water level upstream of the embankment was raised to a height of $6 \mathrm{~m}$ above the impermeable base (Fig. 1b). A grid of 30 by 20 elements was used for the baseline simulation, and was continued until reaching steady-state conditions. For the simulations with different soil types (Sand, Silt, Clay), we varied the widths of the rectangular embankments such that the embankments are stable. Those simulations are documented in Section 3.2.1.

Vertical walls were modeled because the simulated flow rates and water pressures are more forthright and unhindered when entering and exiting the embankments. 
The main purpose of the simulations in this study is to evaluate the hydraulic performance of recycled materials (RM and FA), so the embankment design may not be practically feasible.

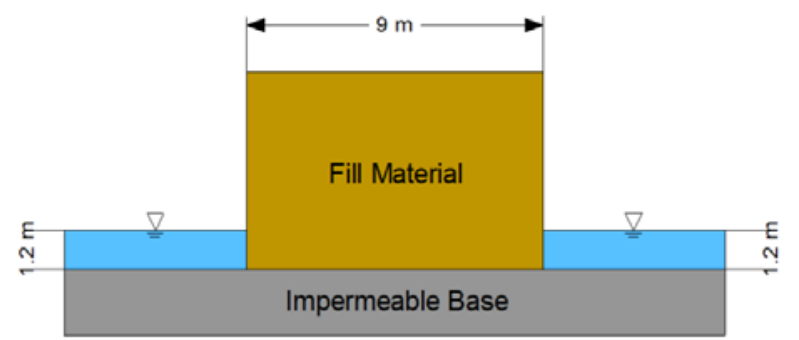

Fig. 1a. The initial water levels of the embankment simulation

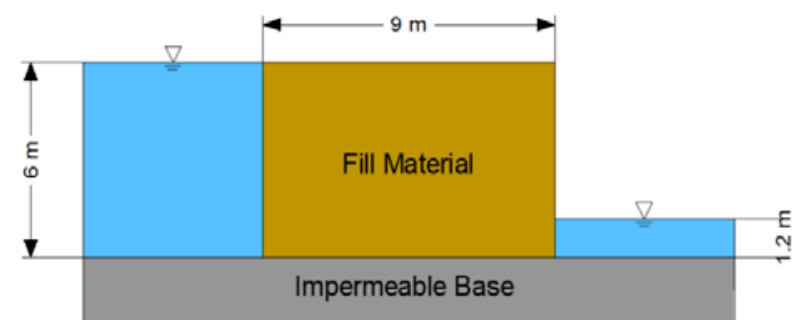

Fig. 1b. The final water levels at its steady state of the embankment simulation

\subsubsection{Seki Webtool}

The nonlinear fitting software's web interface -SWRC Fit [10], was utilized to generate van Guenuchten parameters from the centrifugate data obtained from [2,9]. The centrifuge data was inputted as soil water retention curves (suction head versus volumetric water content), and the Webtool returned the results. The return parameters are the saturated water content $\left(\theta_{\mathrm{s}}\right)$, residual water content $\left(\theta_{\mathrm{r}}\right)$, and shape parameters for the van Genuchten model $(\alpha, \mathrm{m}$, and $\mathrm{n})$.

\subsection{3 van Genuchten equations}

To apply FLAC simulations for Red Mud, Fly Ash, and typical soils, van Genuchten parameters are necessary as a function of suction and saturation, following equations $1,2,3$, and 4 .

$\theta(h)=\theta_{r}+\frac{\theta_{s}-\theta_{r}}{\left(1+|\alpha h|^{n}\right)^{m}}\left(m=1-\frac{1}{n} ; n>1\right)$

Where $\theta(h)$ is the volumetric water content $\left(\mathrm{m}^{3} / \mathrm{m}^{3}\right), \theta_{r}$ is the saturated water content; $\theta_{r}$ is the residual water content; $\alpha$ is the van Genuchten parameter $\left(\mathrm{m}^{-1}\right)$; $\mathrm{h}$ is the pressure head $(\mathrm{m}) ; \mathrm{m}$ and $\mathrm{n}$ are shape parameters.

$$
K(h)=K_{s} S_{e}^{l}\left[1-\left(1-S_{e}^{\frac{1}{m}}\right)^{m}\right]^{2}
$$

Where $K(h)$ is the unsaturated hydraulic conductivity $(\mathrm{m} / \mathrm{s}), K_{s}$ is the saturated hydraulic conductivity $(\mathrm{m} / \mathrm{s})$; $S_{e}(\mathrm{~h})$ is effective saturation; $\mathrm{m}, \mathrm{n}$, and 1 are shape parameters.

$$
S_{e}(h)=\frac{\theta(h)-\theta_{r}}{\theta_{s}-\theta_{r}}
$$

where $S_{e}$ is effective saturation; $\theta(h)$ is the volumetric water content $\left(\mathrm{m}^{3} / \mathrm{m}^{3}\right), \theta_{r}$ is the saturated water content; $\theta_{r}$ is the residual water content; $\mathrm{h}$ is the pressure head $(\mathrm{m})$.

The capillary pressure law used in FLAC is in the following van Genuchten form:

$$
P_{c}\left(\theta_{h}\right)=P_{o}\left(S_{e}(h)^{\frac{-1}{m}}-1\right)^{1-m}
$$

where $P_{o}$ is equal to the following:

$$
P_{o}=\frac{\rho_{w} g}{\alpha}
$$

where $\rho_{w}$ is the water density $\left(\mathrm{kg} / \mathrm{m}^{3}\right) ; \mathrm{g}$ is the gravity $\left(\mathrm{m} / \mathrm{s}^{2}\right) ; \alpha$ is the van Genuchten parameter $\left(\mathrm{m}^{-1}\right)$ given by the Seki tool. For typical soils like Sand, Silt, and Clay, used parameters were acquired from Nemes et al. [14], also available at the Seki Webtool. For Red Mud and Fly Ash, parameters were calculated using a fitting approach based on experimental data following a mathematical model developed by van Genuchten [7]. The parameterization is covered in section 3.1.

For two-phase problems, FLAC requires the mobility coefficient $\left(K_{w}\right)$, which is calculated from the relationship between the intrinsic permeability and dynamic viscosity and can be represented by the following equation:

$$
K_{w}=\frac{\mathrm{K}_{s}}{\rho_{w} g}
$$

where $\mathrm{K}_{\mathrm{s}}$ is the saturated hydraulic conductivity $(\mathrm{m} / \mathrm{s}) ; \rho_{w}$ is the water density $\left(\mathrm{kg} / \mathrm{m}^{3}\right) ; \mathrm{g}$ is the gravity $\left(\mathrm{m} / \mathrm{s}^{2}\right)$.

\section{Results and analysis}

\subsection{Centrifuge data and van Genuchten parameters}

Results from centrifugation tests show that the unsaturated hydraulic conductivity of Red Mud and Fly Ash is lower than typical soils in the experimental element level (Fig. 2). Through the centrifuge data and the Seki webtool, soil hydraulic parameters in the analytical form of van Genuchten for RM and FA were calculated.

Shape parameters $\mathrm{m}$ and $\mathrm{n}$ described in equations 1 and 2 were acquired using the Seki's tool, leaving the parameter 1 (a shape parameter) in equation 2 to be determined from curve fitting between the analytical model and experimental data. The shape parameter 1 is obtained until the variance between the experimental data, and the analytical models (equations 1,2, and 3) was the minimum possible. The following outlines the calculation procedures:

1. Calculate $\theta(h)$ from equation 1 with the $\mathrm{m}, \alpha$, and $\mathrm{h}$ values being experimentally measured by Machado et al. [2] and Sindi [9] or determined by the Seki Webtool [10]. 
2. Calculate $\mathrm{S}_{\mathrm{e}}(\mathrm{h})$ from equation 3 with the $\theta(h)$ values obtained in step 1 , and $\theta_{\mathrm{r}}$ and $\theta_{\mathrm{s}}$ values obtained from the Seki webtool [10].

3. Calculate $K(h)$ from equation 2 with the $S_{e}(h)$ from step 2, $\mathrm{m}=0.5$ from the Seki webtool, $\mathrm{K}_{\mathrm{s}}$ values from centrifuge data, and an assumed value for 1 . The $\mathrm{K}_{\mathrm{s}}$ values were $10^{-10} \mathrm{~m} / \mathrm{s}$ for RM and $4.6 \times 10^{-7} \mathrm{~m} / \mathrm{s}$ for FA.

4. Compare the $\mathrm{K}(\mathrm{h})$ value obtained from step 3 with measured centrifuge data.

5. Assume a new 1 parameter and repeat steps 3 and 4, and the unit difference between the two $K(h)$ values (measured versus analytical) is the smallest possible $\left(1.31 \times 10^{-10}\right.$ for $\mathrm{RM}$ and $1.37 \times 10^{-9}$ for FA). The 1 parameters were determined to be 70 for RM and 9 for FA through trial and error.

The van Genuchten model fits the RM centrifuge data well, but not the FA data (Figure 2). Since the analytical model and Seki webtool were developed from typical soil, the two may not fit well for an uncommon material like Fly Ash.

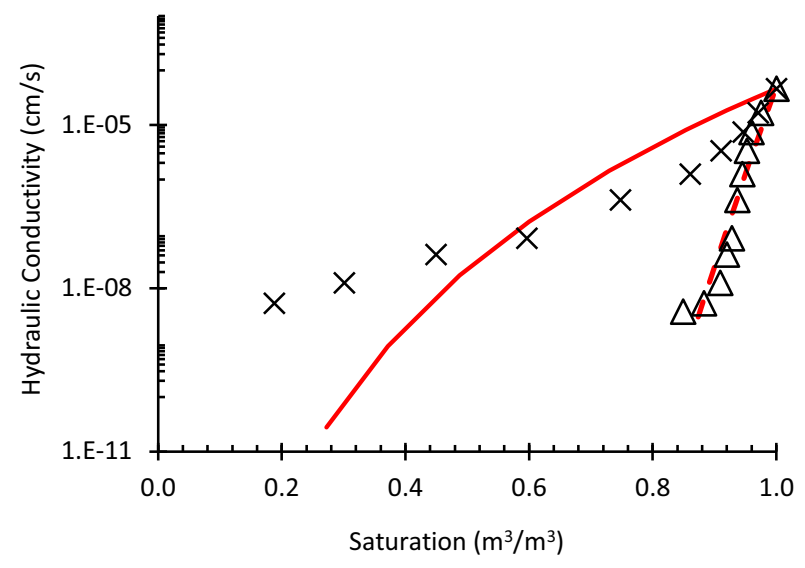

$--\mathrm{RM}-\mathrm{M} \longrightarrow \mathrm{FA}-\mathrm{M} \quad \Delta \quad \mathrm{RM}-\mathrm{E} \quad \mathrm{FA}-\mathrm{E}$

Fig. 2 Unsaturated Hydraulic Conductivity for Fly Ash and Red Mud. $(F A=F l y$ Ash , and RM $=$ Red Mud, $-E=$ Experimental Data, $-M=$ analytical solution)

Matric potentials were also measured for the RM and FA specimens following the ASTM D6527 procedure [11]. Figure 3 shows the experimental data for RM and FA compared with data from typical soils of Clay and Silt in the form of matric suction versus saturation. FA demonstrates a matric potential similar to silty soil, while RM is between clayey and silty soils. However, when close to full saturation, the two residues have a matric potential approaching the sand curve. The van Genuchten model (equations 1 and 2) was also used to calculate the volumetric water content and effective saturation and compared to the experimentally measured volumetric water content at each of the matric suction values. The analytical form matches well with the centrifuge data (Figure 3).

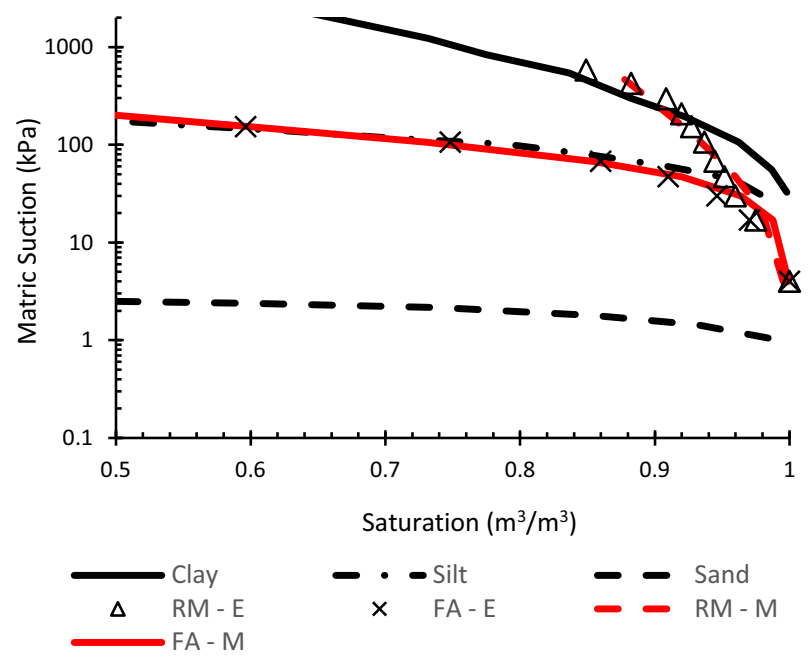

Fig. 3. Soil Water Retention Curves (FA $=$ Fly Ash, and $R M=$ Red Mud, $-E=$ Experimental Data, $-M=$ analytical solution)

Table 1 and Table 2 summarize the parameters for the relative permeability laws with the van Genuchten form used in FLAC 8.1 simulations of water flow through above-ground embankments. For Sand, Silt, and Clay, the values of saturated hydraulic conductivity $\left(\mathrm{K}_{\mathrm{s}}\right)$ were acquired from Terzaghi et al. [15], and the other van Genuchten parameters were obtained from the Nemes et al. [14].

Table 1. Hydraulic Parameters of tested soils

\begin{tabular}{|c|c|c|c|c|c|}
\hline \multirow{2}{*}{} & $\boldsymbol{\theta}_{\mathbf{r}}$ & $\boldsymbol{\theta}_{\mathbf{s}}$ & $\boldsymbol{\alpha}$ & $\mathbf{K}_{\mathbf{s}}$ & $\mathbf{K}_{\mathbf{w}}$ \\
\cline { 2 - 6 } & \multicolumn{2}{|c}{$\mathrm{m}^{3} / \mathrm{m}^{3}$} & $1 / \mathrm{m}$ & $\mathrm{m} / \mathrm{s}$ & $\mathrm{m}^{2} / \mathrm{P}_{\mathrm{a}}-\mathrm{s}$ \\
\hline Sand & 0.1035 & 0.34 & 2.033 & $1 \mathrm{E}-7$ & $1.02 \mathrm{E}-10$ \\
\hline Silt & $4.81 \mathrm{E}-4$ & 0.46 & 1.594 & $1 \mathrm{E}-9$ & $1.02 \mathrm{E}-11$ \\
\hline Clay & $8.23 \mathrm{E}-8$ & 0.55 & 0.082 & $1 \mathrm{E}-9$ & $1.02 \mathrm{E}-13$ \\
\hline $\begin{array}{c}\text { Red } \\
\text { Mud }\end{array}$ & $6.17 \mathrm{E}-6$ & 0.43 & 3.018 & $1 \mathrm{E}-10$ & $5.10 \mathrm{E}-11$ \\
\hline Fly Ash & $8.78 \mathrm{E}-4$ & 0.30 & 0.940 & $4.6 \mathrm{E}-7$ & $4.70 \mathrm{E}-11$ \\
\hline
\end{tabular}

Table 2. Shape Parameters of tested soils

\begin{tabular}{|c|c|c|c|c|}
\hline & $\mathbf{n}$ & $\mathbf{m}$ & $\mathbf{l}$ & $\mathbf{P}_{\mathbf{o}}(\mathbf{k P a})$ \\
\hline Sand & 6.561 & 0.848 & 0.5 & 4.92 \\
\hline Silt & 1.087 & 0.080 & 0.5 & 6.27 \\
\hline Clay & 1.113 & 0.101 & 0.5 & 121.76 \\
\hline Red Mud & 1.048 & 0.046 & 70 & 3.31 \\
\hline Fly Ash & 1.944 & 0.486 & 9 & 10.63 \\
\hline
\end{tabular}

\subsection{FLAC 8.1 Simulation Results}

The FLAC models simulate water flow through the initially dry embankment and reveal the downstream face's seepage condition. The single-material and idealized embankment would enable us to evaluate the material's unsaturated hydraulic performance as fill material in civil engineering applications. We considered a wide range of materials: Clay, Sand, Silt, Red Mud, and Fly Ash. 


\subsubsection{Common Soils (Sand, Silt, and Clay)}

Embankments made up of common soils of Sand, Silt, and Clay were firstly modeled. To allow water to flow through the embankment successfully, the embankment width was changed when the water levels (upstream and downstream) and embankment height were kept constant. We used a width of $100 \mathrm{~m}$ for sand, $9 \mathrm{~m}$ for Silt, and $3 \mathrm{~m}$ for Clay so that the water would flow out at the lower corner of the downstream face. Figures 4 to 6 show the contour plots of pore pressure and flow vectors at the steady state for each of the common soils. At steady state, the water mainly flowed through, and the generation of pore pressures was similar in all three cases. Positive pore pressures were generated at the bottom of the embankments, and negative pore pressures were generated at the top downstream face where they were still unsaturated, creating suction forces.

Figure 7 shows the flow rate $\left(\mathrm{m}^{3} /\right.$ year $)$ at the upstream seepage face. As expected, Clay has the lowest flow rate, and sand has the highest.

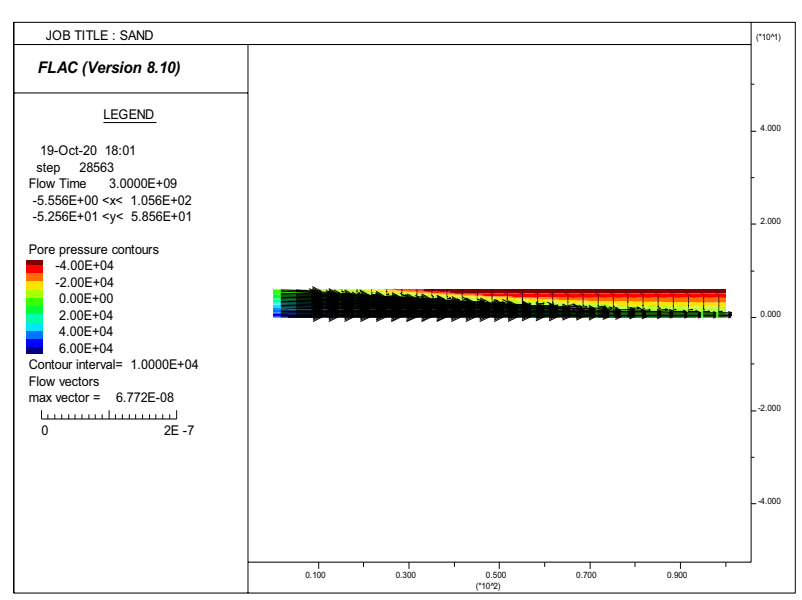

Fig. 4 Contour of pore pressure and flow vectors plot at steady state for an idealized sand embankment with a width of 100 meters

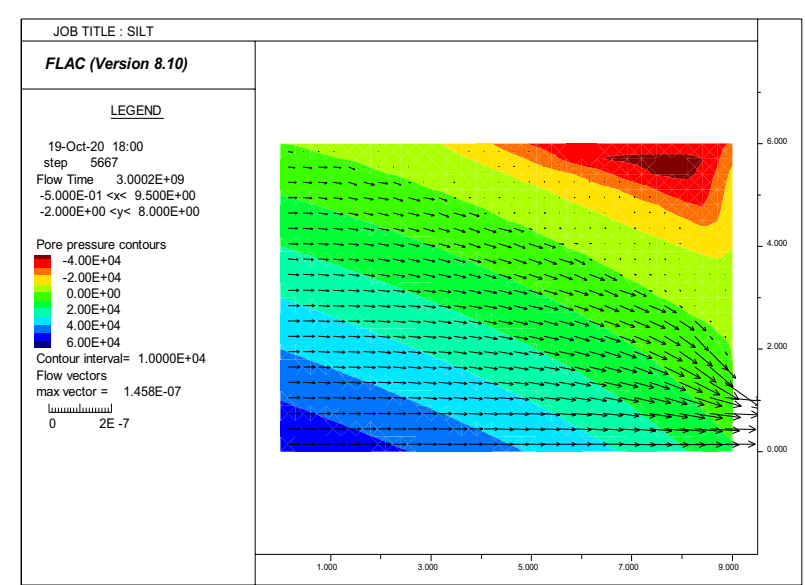

Fig. 5 Contour of pore pressure and flow vectors plot at steady state for an idealized silt embankment with a width of 9 meters

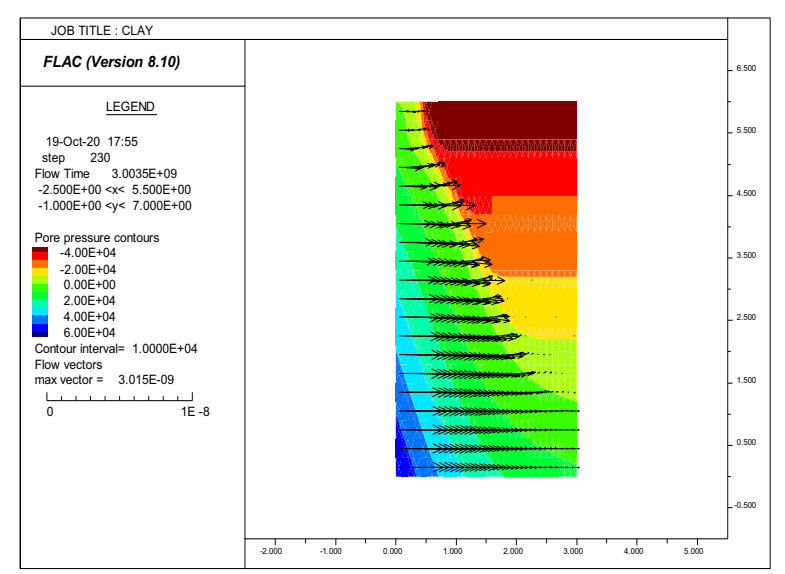

Fig. 6 Contour of pore pressure and flow vectors plot at steady state for an idealized clay embankment with a width of 3 meters

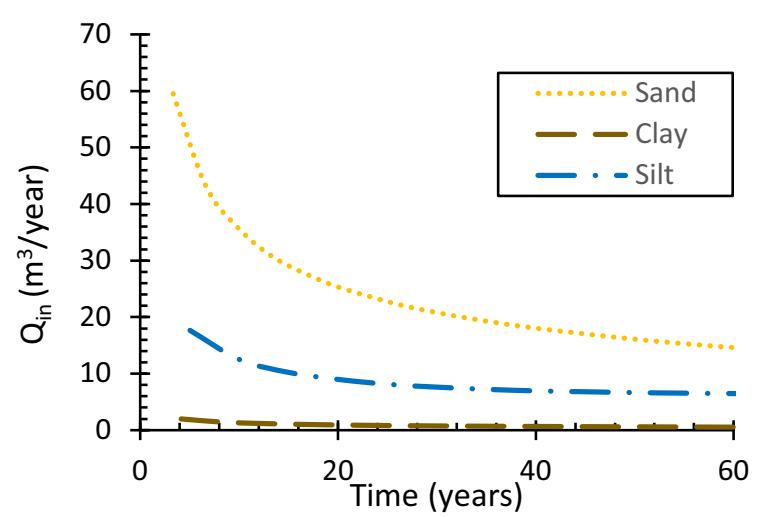

Fig. 7 FLAC simulation inflow values $\left(Q_{i n}\right)$ for typical soils (Sand, Clay, and Silt).

\subsubsection{Red Mud and Fly Ash}

Figures 8 and 9 show the contour pore pressure and flow vector plots at steady state for the Red Mud and Fly Ash embankments. The width of the embankments is 9 meters, same as the silt embankment in section 3.2.1. The developed pore pressures at steady state in the FA embankment (Figure 9) were very close to those generated in the silt one (Figure 5). However, there were relatively more excess pore pressures generated in the RM embankment, which would adversely affect the embankment's stability.

Figures 10 and 11 depict the inflow rate at the upstream seepage face and outflow rate at the downstream seepage face for RM and FA and compared with those from the silt embankment simulation. Since the three embankments all have a width of $9 \mathrm{~m}$, we can compare the results in flow rates. The results show that the flow rates entering and leaving RM and FA embankments are similar, and both are higher than those flow rates $\left(Q_{\text {in }}\right.$ and $Q_{\text {out }}$ in the silty soil (Figures 10 and 11). The simulations show the RM and FA embankments are more permeable than the Silt one, and are consistent with the recorded matric behavior from the centrifuge tests. When the samples of RM and FA were getting close to full saturation, the matric responses of RM and FA are behaving more like sand than silt (Figure 3). 


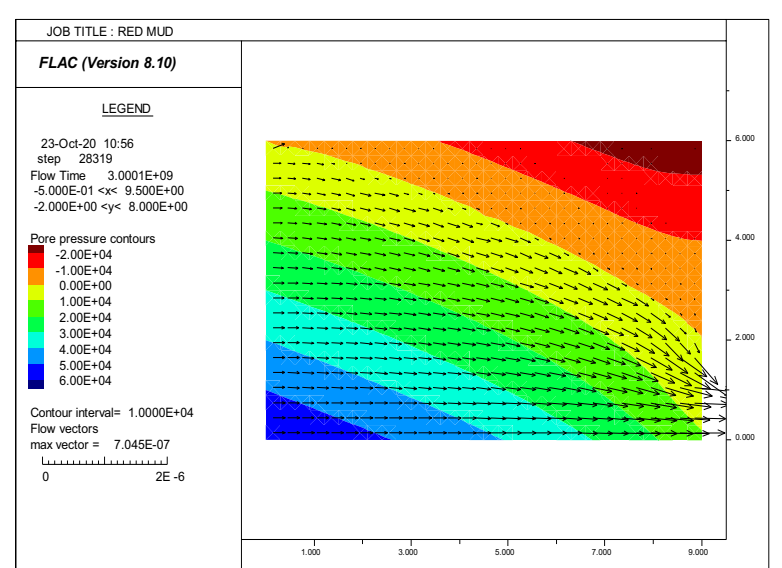

Fig.8. Contour of pore pressure and flow vectors plot at steady state for an idealized Red Mud embankment with a width of 9 meters.

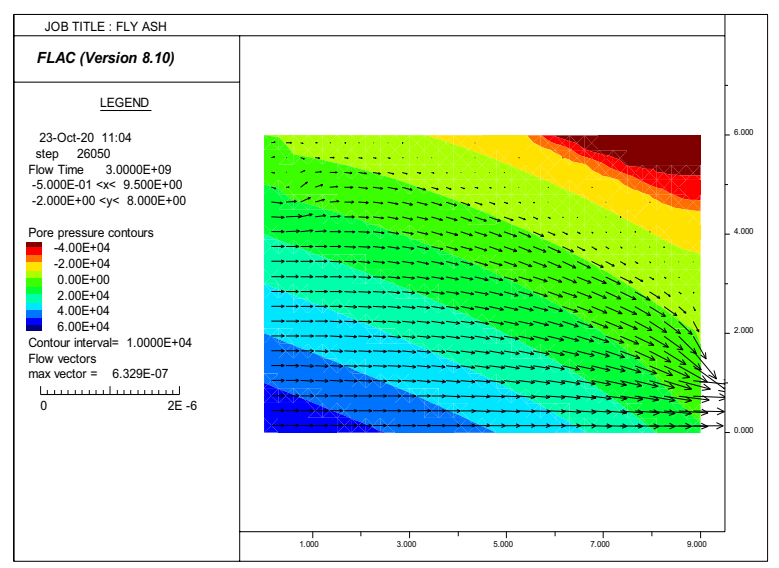

Fig.9. Contour of pore pressure and flow vectors plot at steady state for an idealized Fly Ash embankment with a width of 9 meters.

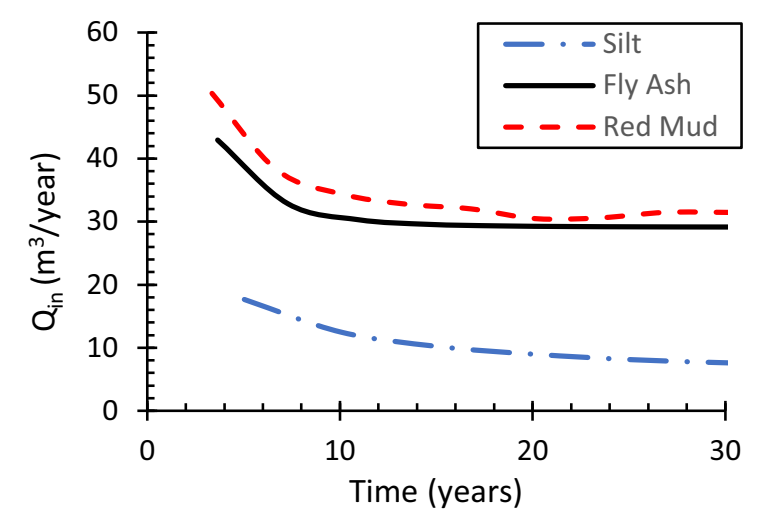

Fig. 10. FLAC simulation inflow values $\left(Q_{\text {in }}\right)$ for Fly Ash and Red Mud compared to typical soils (Silt).

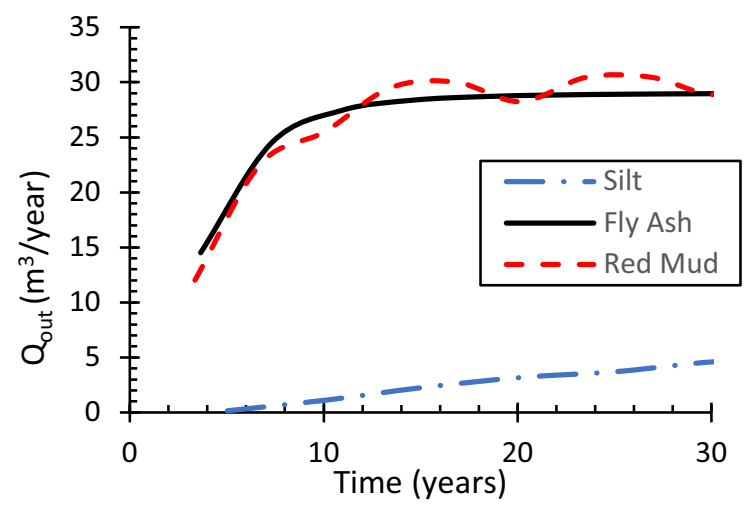

Fig. 11. FLAC simulation outflow values ( $\left.Q_{\text {out }}\right)$ for Fly Ash and Red Mud compared to typical soils (Silt).

\section{Conclusion}

This research study evaluated the feasibility and sustainability of using Fly Ash and Red Mud, two broadly available residues from Coal and Aluminium production, respectively, in a civil engineering application as a fill material for above-ground embankments. Idealized embankments, composited with one single material (Silt, Fly Ash, and Red Mud), were simulated in FLAC 8.1 with the two-phase option using the van Genuchten model to evaluate the material's hydraulic performance as a geostructure. The van Genuchten model parameters for Fly Ash and Red Mud were developed by an unsaturated flow apparatus to perform steady-state centrifugation tests at Cal State LA. The results show the van Genuchten model works well in fitting the Red Mud data, but not Fly Ash data. The numerical simulations show that Red Mud and Fly Ash have a higher flow tendency than a typical silty soil. Moreover, relatively higher excess pore pressures were generated in the Red Mud embankment than the Fly Ash. The simulation results show the two residues are less appealing to be used as fill materials in above-ground embankments than silty soil for retarding water flow.

\section{Acknowledgments}

This work was supported by the Cal State LA CREST Center for Energy and Sustainability (CEaS) of the National Science Foundation (NSF) - United States under NSF Award Number HRD 1547723 and the Department of Civil Engineering. Any opinions, findings, conclusions, or recommendations expressed in this material are those of the authors and do not necessarily reflect those of the NSF.

\section{References}

1. International Aluminum Institute. (2015). Bauxite residue best practices. Eur. Alum. Assoc. https://www.world-aluminium.org/

2. J. Machado, W. Kwan, M. Gore, G. Menezes. (2020). Comparison of advanced hydraulic properties between treated and untreated bauxite residue. $2^{\text {nd }}$ Intern. Conf. on Ener. Geotechnics. doi: 10.1051/e3sconf/202020512002 
3. R. S. Blisset \& N.A. Rowson. (2012). A review of the multi-component utilisation of coal fly ash. Fuel. 97, 1-23. doi: 10.1016/j.fuel.2012.03.024

4. M. Gore. (2015). Geotechnical Characterization of Bauxite Residue (Red Mud). Ph.D. Dissertation, The University of Texas at Austin

5. D.G. Fredlund, H. Rahardjo, M.D. Fredlund. (2012). Unsaturated Soil Mechanics in Engineering Practice (John Wiley \& Sons)

6. Itasca. (2016). Fast Lagrangian Analysis of Continua User's Guide Version 8.0. https://www.itascacg.com/

7. M. van Genuchten. (1980). A closed-form equation for predicting the hydraulic conductivity of unsaturated soils. Soil Sci. Soc. Am. J. 44, 892- 898

8. E. C. Leong, H. Rahardjo. (1997). Review of soilwater characteristic curve equations. J. of Geotech. And Geonv. Eng. 123, 1106-1117.

9. H. Sindi. (2019). Characterizing unsaturated hydraulic properties of compacted coal combustion by-products using steady state centrifugation unsaturated flow apparatus. M.S. Thesis, California State University, Los Angeles.

10. K. Seki. (2007). SWRC fit - a nonlinear fitting program with a water retention curve for soils having unimodal and bimodal pore structure. Hyd. Earth. Syst. Sci. Disc. 4, 407-437.

11. ASTM D 6527-00 (2008). Standard test method for determining unsaturated and saturated hydraulic conductivity in porous media by steady state centrifugation. ASTM International, www.astm.org

12. Itasca. (2016). FLAC Version 8.0 Fluid-Mechanical Interaction. www.itascacg.com

13. P.A. Forsyth, Y.S. Wu, K. Pruess. (1995). Robust numerical methods for saturated - unsaturated flow with dry initial conditions in heterogeneous media. Advances in Water Resources. 18, 25-38.

14. A. Nemes, M.G. Shaap, F.J., Leij., J.H.M. Wosten. (2001). Description of the unsaturated soil hydraulic database UNSODA version 2.0. J. Hydrol (Amsterdam). 251, 151-162.

15. K. Terzaghi, R. B. Peck, G. Mesri. (1996). Soil mechanics in engineering practice $3^{\text {rd }}$ Ed (John Wiley \& Sons) 